Int. J. Odontostomat., 8(2):185-189, 2014.

\title{
Tuberous Sclerosis: A Case Report with Oral Manifestation
}

\author{
Esclerosis Tuberosa: Caso Clínico con Manifestaciones Orales
}

\begin{abstract}
Marcos Martins Curi"; Camila Lopes Cardoso ",; Carla Renata Sanomiya Ikuta*; Daniel Henrique Koga* \& Cristina Zardetto*
\end{abstract}

CURI, M. M.; CARDOSO, C. L.; IKUTA, C. R. S.; KOGA, D. H. \& ZARDETTO, C. Tuberous sclerosis: a case report with oral manifestation. Int. J. Odontostomat., 8(2):185-189, 2014.

ABSTRACT: Tuberous sclerosis is an autosomal dominant neurocutaneous syndrome, which may involve multiple organ systems and shows highly variable clinical manifestations. Oral manifestations, including lesions on hard tissues, enamel hypoplasia and gingival hyperplasia have been previously described. We report a case of 25 -year-old woman with this syndrome presenting multiple fibrous nodules on the buccal mucosa and lips. Awareness of the different oral manifestations of tuberous sclerosis is important to ensure appropriate diagnosis and treatment.

KEY WORDS: tuberous sclerosis, autosomal dominant, oral manifestation.

\section{INTRODUCTION}

Tuberous sclerosis (TS) complex is an autosomal dominant disease with largely variable clinical manifestations. It belongs to the neurocutaneous disorders, or phacomatoses, such as neurofibromatosis, von Hippel-Lindau syndrome, and Sturge-Weber syndrome (Scully, 1977). The first to describe the disease was von Recklinghausen, in 1862, in a newborn child with multiple cardiac and brain tumors. However, the term TS was coined years later by Bourneville and Pringle who described the association of renal and cerebral lesions, but without cutaneous manifestations (Crino \& Henske, 1999). In 1908, Vogt linked seizures, mental retardation and adenoma sebaceum (facial angiofibromas), known as the Vogt triad. This triad is only seen in a third of the cases (Morse, 1998). The incidence of TS ranges from $1 / 10,000$ to $1 / 500,000$, depending on the study (Scully, 1981; Gomez, 1988).

Two tumor suppressing genes, TSC1 and TSC2, are though to be responsible for the pathogenesis of TS and are located on chromosomes $9 q$ and $16 p$, respectively (Fryer et al., 1987). About two thirds of cases are new mutations in patients with no family history of this disorder. An identifiable mutation has not yet been found to explain the remainder of cases (Kwiatkowska et al., 1998). The disease has greater than 95\% penetrance. However, phenotypic differences have been identified between TSC1 and TSC2 mutations (Kwiatkowska et al.). The incomplete expression of the disease or "forme fruste", first described by Schuster in 1914 , is responsible for many undiagnosed cases of this disorder. Due to these complexities, the diagnosis of TS is currently based on clinical findings and genetic testing is indicated for research studies only.

The diagnostic criteria for TS were developed by Gomez using both clinical and radiographic evidence. They are categorized into major and minor criteria and any of them are diagnostic features by themselves. The definitive diagnosis is reached whenever patients present 2 major or 1 major plus 2 minor findings on examination. The organs most commonly affected are the brain, skin, kidneys, heart, eyes, and lung. The most frequent neurological manifestations are the cortical tubers, found in more than $80 \%$ of patients with TS, leading to seizure disorders and mental retardation (Lendvay \& Marshall, 2003). Up to $98 \%$ of patients with TS have seizures, $75 \%$ within the first year of life. However, patients may have cortical tubers without seizures and mental retardation (Lendvay \& Marshall).

* DDS, MSc, PhD, Department of Stomatology, Hospital Santa Catarina, São Paulo, Brazil.

* DDS, MSc, Department of Stomatology, Bauru Dental School, University of São Paulo, São Paulo, Brazil. 
Dermatological manifestation of TS are prevalent findings. The most common skin lesion is the hypomelanotic macule or "ash-leaf" spot named as such because of its resemblance to the European mountain ash tree (Scully, 1977). Another characteristic skin lesion of TS is the misnomer "adenoma sebaceum" or facial angiofibroma, a vesicopapular rash that are typically distributed in a symmetric "butterfly pattern", along the nasolabial folds, cheeks, chin, and less commonly on the forehead and scalp (Lendvay \& Marshall). Angiofibromas that affect the lumbosacral skin region have been termed Shagreen patches. Other dermatological manifestations include café au lait macules, periungual fibromas, vascular nevi, and skin tags (Lendvay \& Marshall).

Renal involvement in TS includes angiomyolipomas, renal cell carcinoma, and polycystic kidney. The most frequent renal lesion is angiomyolipoma composed of disorganized smooth muscle cells, adipose tissue and aberrant vascular structures. Approximately $26 \%$ to $80 \%$ of patients with TS have angiomyolipoma (Lendvay \& Marshall). These lesions are usually asymptomatic, but may cause flank pain and hematuria. Renal pathology is second only to neurological pathology as the primary cause of morbidity and mortality (Lendvay \& Marshall). With a more effective seizure control, renal disease is predicted to become the most common cause of death. Renal disease is usually secondary to replacement of normal parenchyma by tumors or cysts, and nephrectomy may be indicated in severe involvement of the renal parenchyma.

Cardiac rhabdomyoma is sometimes the earliest finding in patients with TS detected on prenatal sonography. This hamartoma of the heart is usually asymptomatic and decreases in $50 \%$ to $75 \%$ of patients by the age 6 years. However, some patients will develop devastating sequelae from this mass (Lendvay \& Marshall). A fetal arrhythmia is the most common sign identified on fetal echocardiography. Cardiac arrhythmia has been the cause of sudden infant death in patients with TS, although the arrhythmias in these patients differ from the ones observed on the general population in their higher rate of regression. Cardiac rhabdomyomas causing refractory arrhythmias may be resected successfully (Lendvay \& Marshall).

There are several nonspecific oral manifestations in patients with TS that are not specific to this disorder (Scully, 1977, 1981; Damm et al., 1999; Sparling et al., 2007). In different studies, oral lesions have been reported to occur in $11 \%$ to $69 \%$ of TS patients (Scully, 1977; Tillman \& De Caro, 1991; Sparling et al.). Oral abnormalities include a large variety of dental, mucosal and skeletal manifestations. Enamel pitting randomly occurs on all tooth surfaces and lacks any chronological orientation. This is a relative common finding on the labial surfaces of the anterior permanent teeth, with up to $100 \%$ of patients showing enamel pitting (Scully, 1977). Mucosal lesions consist mainly of fibrous nodules, often multiple, affecting the anterior gingiva. They may also be found on the tongue, lips, palate and buccal mucosa. Gingival hyperplasia is also seen due to poor oral hygiene and secondary to anticonvulsant therapy. Other oral manifestations include hemangiomas, hyperostosis, cleft lip and palate, high arched palate, macroglossia, bifid uvula, facial asymmetry and diastema. Reports of intra-osseous fibroblastic lesions in the maxillofacial complex include calcifying epithelial odontogenic tumor, odontogenic myxoma, odontogenic fibroma and desmoplastic fibroma (Lendvay \& Marshall; Harrison et al., 1997; Lygidakis \& Lindenbaum, 1989).

TS may have distinct oral manifestations that may help identify or confirm the diagnosis of this disease. This report describes the oral manifestation of TS in a patient that had not been previously diagnosed until skin biopsy was performed.

\section{CASE REPORT}

A 25-year-old woman was referred to the Stomatology Department by her pelvic surgeon for evaluation of multiple oral lesions located on the oral mucosa. Medical history revealed that the patient had been admitted at this institution at the age of 15 with a presumptive diagnosis of leimyosarcoma on the left kidney. Medical investigation revealed bilateral renal angiomyolipomas. The patient had been treated with partial nephrectomy of the left kidney and total nephrectomy of the right kidney. No recurrence was observed during the last couple of years. There was no family history of tuberous sclerosis (TS), epilepsy, or mental handicap. The diagnosis of TS had not been made until a skin biopsy was performed, 10 years later, at the same time that she was referred for oral evaluation.

Initial physical examination revealed numerous small, smooth, normal colored nodules distributed in a butterfly pattern over the paranasal areas, cheeks and nasolabial folds (Fig. 1). These nodules represented 
facial angiofibromas and varied in size from 1 to $3 \mathrm{~mm}$. An additional finding of a hypomelanotic macule or "ash-leaf" spot was evident on the trunk (Fig. 2). A review of the medical record revealed intracranial calcifications observed on a computed tomography (CT) scan (Fig. 3), and further physical investigation showed a retinal (astrocytic) hamartoma.

Intra-oral examination revealed permanent dentition and relatively good hygiene. Examination of the soft tissues showed multiple fibrous nodules located on the buccal and lip mucosas (Fig. 4). The nodules were of normal mucosal color and varied in size up to $3 \mathrm{~mm}$. The

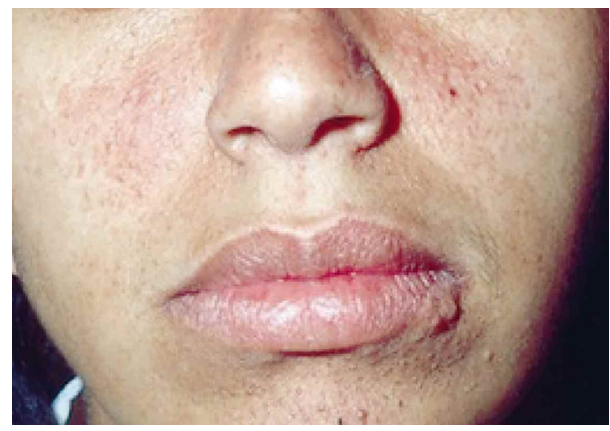

Fig. 1. Facial photograph showing butterfly pattern of numerous angiofibromas.

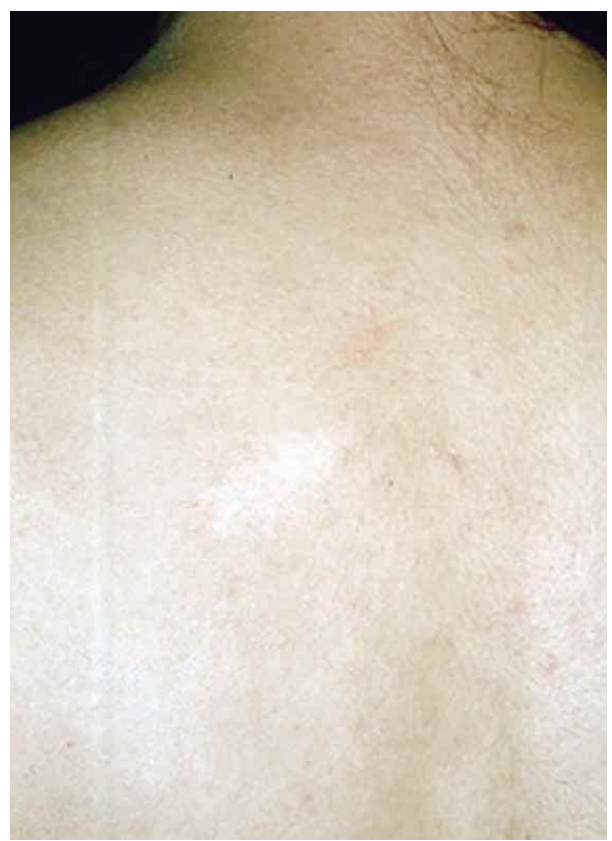

Fig. 2. Hypopigmented "ash-leaf" lesion on trunk. patient was not aware of the oral lesions. An excisional biopsy of a nodular lesion on the buccal mucosa was done. Histologically, it was composed of orthokeratinized epithelium with an underlying dense fibrous connective tissue. No dental abnormalities or gingival hyperplasia were noted.

The panoramic radiograph revealed no jaw abnormalities. Hematological results and urinalysis were normal. Auscultation of the heart and lungs revealed no abnormalities. The patient received oral hygiene instructions and has been recalled for follow-ups every 4months.

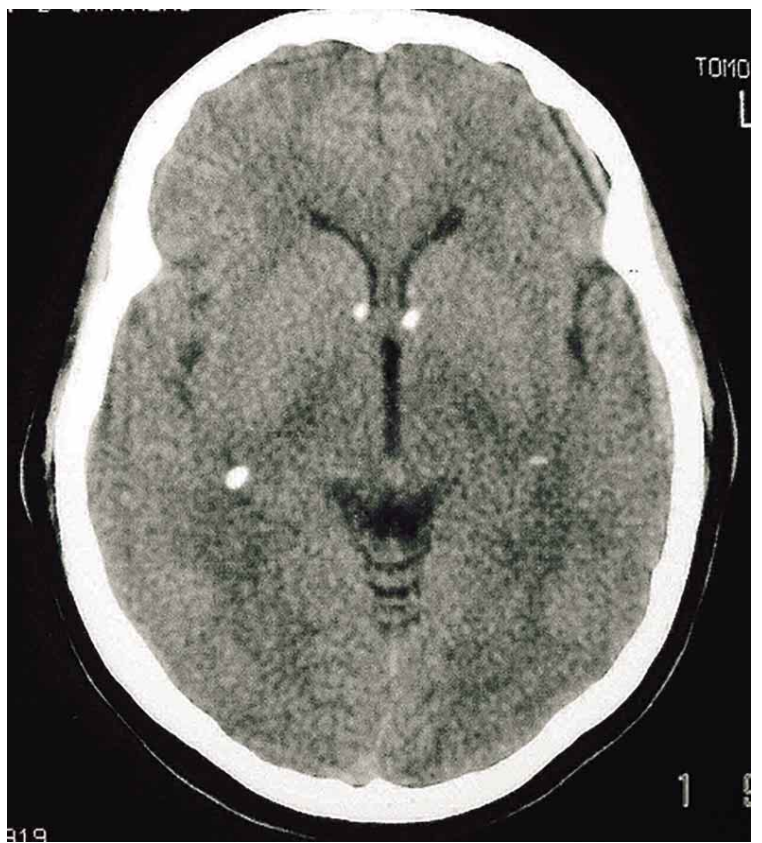

Fig. 3. Soft tissue window CT scan shows scattered cranial calcifications.

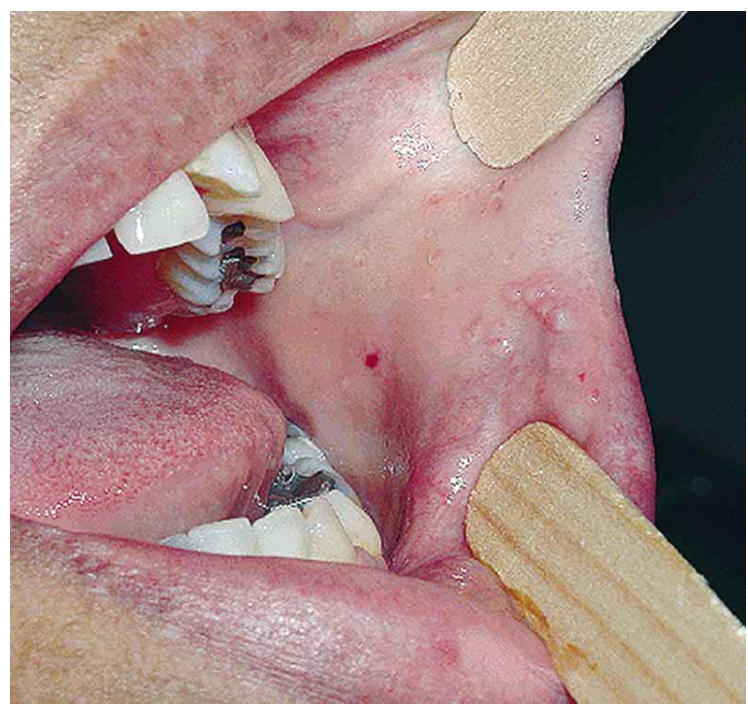

Fig. 4. Intraoral photograph shows discrete fibrous lesions on the lip and buccal mucosas. 


\section{DISCUSSION}

The clinical features of facial angiofibromas (adenoma sebaceum), hypopigmented macule (ashleaf), bilateral renal angiomyolipomas and retinal hamartoma in this patient confirmed the diagnosis of TS (Bourneville-Pringle syndrome; Bourneville's disease; epiloia). In a recent clinical study of 58 adults with TS, 40 patients had $(69 \%)$ had oral fibromas and 97\% had multiple dental enamel pits (Sparling et al.). Another study with 39 patients with typical TS revealed oral fibromas in $56 \%$ of the cases (Lygidakis \& Lindenbaum). The oral lesions found in the present case were compatible with the diagnosis of TS and have been reported in other cases (Gomez; Lygidakis \& Lindenbaum; Sparling et al.).

It has been suggested that fibrous or papillomatous hyperplasias may be secondary to anticonvulsant therapy, such as phenytoin, for neurologic manifestations and are not true TS lesions (Lygidakis \& Lindenbaum). It is well known that phenytoin plays a role in gingival hyperplasia. However, it usually affects the gingiva, particularly the interdental papilla, and does not produce fibromas on the buccal mucosa, lips, tongue and palate, preferential sites in patients with TS. The oral lesions found in the present case, papillomatous hyperplasia, involved the buccal mucosa and lips and did not resemble those usually seen in association with anticonvulsant therapy that are homogeneous, generalized gingival hyperplasias. Finally, similar mucosal lesions have been found in patients with TS who had never been treated with phenytoin or any other anticonvulsant drugs (Gomez; Lygidakis \& Lindenbaum).

Mental retardation may impair the dental management and oral hygiene maintenance, particularly when deep sedation or general anesthesia is needed, in patients with TS. Our patient had no history of mental retardation or epileptic crises, never used anticonvulsant drugs and was able to achieve a reasonably good oral hygiene. Since the oral lesions were not of concern to the patient, there was no need to remove them.

Treatment of TS is palliative and its prognosis varies and depends on the organs affected by the disease. Renal pathology is second only to neurological pathology as the primary cause of morbidity and mortality, and is the first cause of death in patients older than 30 years (Damm et al.). With the introduction of more effective seizure control, renal disease is predicted to become the most common cause of mortality (Damm et al.). The most common renal lesion is angiomyolipoma. Up to $84 \%$ of TS angiomyolipomas are bilateral (Damm et al.). Although most of the patients are asymptomatic, persistent hemorrhage caused by increased vascularization of the angiomyolipomas may cause flank pain and kidney failure. The management of these lesions has been correlated to size of tumor and has included embolization, partial nephrectomy or total nephrectomy (Damm et al.). Our patient had been treated with partial nephrectomy because of excessive bleeding in both kidneys and no additional measures were necessary.

When managing patients with a syndrome bearing a great potential for severe systemic involvement, early diagnosis is essential and may help control the disease. Oral manifestations may help to identify or determine the genetic disorder present. The present case had almost all of the neurological, cutaneous, renal, retinal and oral features of TS although there was no family history. It is important that professionals understand the great variety of clinical manifestations of TS so that the diagnosis can be established and appropriate care provided.

CURI, M. M.; CARDOSO, C. L.; IKUTA, C. R. S.; KOGA, D. H. \& ZARDETTO, C. La esclerosis tuberosa: caso clínico con manifestaciones orales. Int. J. Odontostomat., 8(2):185-189, 2014.

RESUMEN: La esclerosis tuberosa es un síndrome autosómico dominante neurocutáneo, que puede afectar varias partes del cuerpo y las manifestaciones clínicas son variables. Manifestaciones orales que incluyen lesiones en tejidos duros, hipoplasia del esmalte e hiperplasia gingival se han descrito previamente. Este artículo presenta un caso de una mujer de 25 años con esclerosis tuberosa presentando múltiples nódulos fibrosos en la mucosa bucal y los labios. El conocimiento de las diferentes manifestaciones orales de la esclerosis tuberosa es importante para asegurar el diagnóstico y tratamiento adecuados.

PALABRAS CLAVE: esclerosis tuberosa, síndrome autosómico, manifestaciones orales. 


\section{REFERENCES}

Crino, P. B. \& Henske, E. P. New developments in the neurobiology of the tuberous sclerosis complex. Neurology, 53(7):1384-90, 1999.

Damm, D. D.; Tomich, C. E.; White, D. K. \& Drummond, J. F. Intraosseous fibrous lesions of the jaws: a manifestation of tuberous sclerosis. Oral Surg. Oral Med. Oral Pathol. Oral Radiol. Endod., 87(3):334-40, 1999.

Fryer, A. E.; Chalmers, A.; Connor, J. M.; Fraser, I; Povey, S.; Yates, A. D.; Yates, J. R. \& Osborne, J. P. Evidence that the gene for tuberous sclerosis is on chromosome 9. Lancet, 1(8534):659-61, 1987.

Gomez, M. R. Tuberous sclerosis. $2^{\text {nd }}$ ed. New York, Raven Press, 1988. pp.1-20, 179-89, 213-31, 257-9.

Harrison, M. G.; O'Neill, I. D. \& Chadwick, B. L. Odontogenic myxoma in an adolescent with tuberous sclerosis. J. Oral Pathol. Med., 26(7):339-41, 1997.

Kwiatkowska, J.; Jozwiak, S.; Hall, F.; Henske, E. P.; Haines, J. L.;McNamara, P.; Braiser, J.; Wigowska-Sowinska, J.; Kasprzyk-Obara, J.; Short, M. P. \& Kwiatkowski, D. J. Comprehensive mutational analysis of the TSC1 gene: observations on frequency of mutation, associated features, and nonpenetrance. Ann. Hum. Genet., 62(Pt. 4):277-85, 1998.

Lendvay, T. S. \& Marshall, F. F. The tuberous sclerosis complex and its highly variable manifestations. J. Urol., 169(5):1635-42, 2003.

Lygidakis, N. A. \& Lindenbaum, R. H. Oral fibromatosis in tuberous sclerosis. Oral Surg. Oral Med. Oral Pathol., 68(6):725-8, 1989.

Morse, R. P. Tuberous sclerosis. Arch. Neurol., 55(9):12578, 1998.

Scully, C. Oral mucosal lesions in association with epilepsy and cutaneous lesions: the Pringle-Bourneville syndrome. Int. J. Oral Surg., 10(1):68-72, 1981.

Scully, C. Orofacial manifestations in tuberous sclerosis. Oral Surg. Oral Med. Oral Pathol., 44(5):706-16, 1977.

Sparling, J. D.; Hong, C. H.; Brahim, J. S.; Moss, J. \& Darling, T. N. Oral findings in 58 adults with tuberous sclerosis complex. J. Am. Acad. Dermatol., 56(5):786-90, 2007.

Tillman, H. H, \& De Caro, F. Tuberous sclerosis. Oral Surg. Oral Med. Oral Pathol., 71(3):301-2, 1991.
Correspondence to:

Camila Lopes Cardoso

Department of Stomatology

Oncology, Hospital Santa Catarina

Av. Paulista 200, Bela Vista

CEP 04101-000

São Paulo

BRAZIL

Email: cardoso_lopes@yahoo.com.br

Received: 25-07-2013

Accepted: 03-06-2014 